\title{
GESTÃO DO CAPITAL INTELECTUAL
}

\author{
INTELECTUAL ASSET MANAGEMENT
}

Adélcio Machado dos Santos ${ }^{1}$ e Alexandre Carvalho Acosta ${ }^{2}$

Recebido em: 29/08/2016

Aprovado em: 27/09/2016

\section{RESUMO}

Este artigo colima o escopo de, a partir de uma análise bibliográfica, explicar a natureza epistemológica e operacional do capital intelectual. É possível compreender os ativos intangíveis por meio de duas perspectivas diversas. A primeira delas, formulada por Brooking, considera que a empresa é formada por ativos tangíveis e pelo capital intelectual. Esse capital intelectual é dividido em ativos de mercado, ativos humanos, ativos de propriedade intelectual e ativos de infraestrutura. Já a segunda abordagem, porposta por Edvinsson e Malone, entende que a organização se constitui de uma dimensão visível e de uma parte oculta. A parte oculta compreende o capital intelectual, formado pela junção do capital humano com o capital estrutural. Nessas duas abordagens, observase o uso de diferentes terminologias para designar os mesmos objetos: enquanto a primeira emprega a palavra ativo, a segunda utiliza o termo capital. Conclui-se que ambas as expressões estão corretamente empregadas, pois todos os componentes do capital intelectual são elementos essenciais para as empresas, representando recursos ou capital, se vistos pela economia, e ativos - bens e ou direitos - se vistos pela contabilidade, pois estes se enquadram na definição de ativo.

Palavras-chave: Gestão; Capital intelectual. Organização.

\begin{abstract}
This article collimates the scope from bibliographical analysis explain the epistemological and operational of intellectual capital. Two diverging perspectives approach the intangible assets. In the first, it is considered that a company is formed by tangible assets plus the intellectual assets. These intellectual assets are divided by market assets, human assets, property of intellectual assets and infrastructure assets. However, in the second approach it is considered that the company is formed by a visible and an invisible part. The invisible part comprises the intellectual capital, formed by joining the human capital to the structural capital. These two approaches, the first one by Brooking and the second one by Edvinsson and Malone, two differences concerning terminologies are observed when referring to the same objects: while one author uses the word asset, the others use the word capital. We conclude that although they are correctly put, all the components of the intellectual capital are essential to the companies, representing the resources or capital, according the economy, and assets - goods and duties - according to accountancy are considered assets.
\end{abstract}

Keywords: Management; Intellectual capital; Organization.

1 Escritor, pesquisador e professor do Programa de Mestrado em Desenvolvimento e Sociedade da Universidade Alto Vale do Rio do Peixe (UNIARP) E-mail: adelciomachado@gmail.com alexandre@alexandreacosta.com 


\section{Introdução}

O capital intelectual é concebido por Brooking (1996 apud ANTUNES, 2000), como uma combinação de ativos intangíveis, frutos das mudanças nas áreas da tecnologia da informação, mídia e comunicação, os quais trazem benefícios intangíveis para as organizações, possibilitando, assim, seu funcionamento. Para Stewart (2002 apud MENDES, 2005), o capital intelectual é a soma do conhecimento de todos em uma empresa, ou seja, é a soma do conhecimento tácito da força de trabalho, das informações da estrutura organizacional, dos processos mapeados, do registro de propriedade intelectual e das demais experiências que podem ser codificadas e empregadas em prol da geração de riqueza e novos produtos.

O capital intelectual poderá estar nos processos organizacionais, armazenado em sistemas específicos ou, então, nas cabeças das pessoas que formam a organização. Nesse último caso, o capital intelectual recebe também a denominação de capital humano, formado pelo conhecimento tácito existente no indivíduo (STEWART, 2002 apud MENDES, 2005).

Ainda conforme Stewart (2002 apud MENDES, 2005), o capital humano pode ser considerado um bem latente, esperando para ser identificado, compartilhado e efetivamente empregado pela empresa. Trata-se do início de tudo, isto é, da fonte da inovação, da qual florescem os insights geradores de vantagem competitiva. Para liberar o capital humano que já existente na organização, usando mais o que as pessoas sabem, as empresas precisam criar oportunidades de tornar público o conhecimento privado.

O capital intelectual, no juízo de Antunes (2000), pode ser dividido nas seguintes categorias: a. ativos de mercado - potencial que a organização possui em virtude dos intangíveis, que estão ligados ao mercado, tais como marca, clientes, lealdade dos clientes, canais de distribuição e franquias;

b. ativos humanos - benefícios que o indivíduo pode proporcionar para as empresas por meio de sua criatividade, de seu conhecimento e de sua habilidade para dirimir problemas;

c. ativos de propriedade intelectual -ativos que precisam de proteção legal no intento de garantirem às organizações benefícios, tais como know how, segredos industriais, copyright, patentes e designs;

d. ativos de infraestrutura -ativos na forma de tecnologias, de metodologias e de processos empregados como cultura, sistema de informação, métodos gerenciais, aceitação de risco, banco de dados de clientes, entre outros.

Outra classificação apresentada pelos teóricos Edvinsson e Malone (1998 apud ANTUNES, 2000) é a seguinte:

a. capital humano - formado pelo conhecimento, pelo poder de inovação e pela habilidade dos funcionários, juntamente com os valores, a cultura e a filosofia da empresa;

b. capital estrutural - constituído dos equipamentos de informática, dos softwares, do banco de dados, das marcas registradas, do relacionamento com os clientes, bem como das demais capacidades organizacionais que asseguram o devido apoio à produtividade dos empregados. 
O capital intelectual abrange diversos elementos intangíveis, além do próprio capital humano. Sendo assim, o capital intelectual abarca o elemento possuidor dos recursos do conhecimento e tudo o que é decorrente da aplicação desse conhecimento, já que o conhecimento lato e stricto se materializam no capital estrutural e nos ativos de mercado.

Este artigo objetiva, assim, analisar em profundidade os direcionamentos da gestão do capital intelectual e das próprias organizações que oferecem essa modalidade administrativa. Ademais, pretende-se levantar as ambiguidades e contradições que circundam este construto, a partir de uma revisão de bibliografia. Para tanto, parte-se da apresentação histórica do fenômeno no Brasil, para, na sequência, clarificar a conceituação do tema em análise. Uma vez esclarecido o verdadeiro significado do termo, passa-se para o problema da sua aplicação.

\section{Referencial teórico}

Ressalte-se que, por vezes, o capital intelectual e o capital humano são confundidos, entendendo-se como capital intelectual somente aquele que resulta do conhecimento humano. Segundo Antunes (2000), isso se deve à relevância do ser humano enquanto possuidor do recurso fundamental do conhecimento.

Como o ativo humano ou capital humano compreende os benefícios que o indivíduo pode propiciar para as organizações, é natural que as empresas dediquem maiores esforços para identificar aquelas pessoas que poderão otimizar essa relação de causa e efeito. Quanto melhor é o capital humano de uma empresa, afirma Antunes (2000), melhores serão os resultados que ela obterá por meio de seu capital intelectual.

Carbone (2006) entende que, na era do conhecimento, caracterizada por mudanças inconstantes no mundo do negócio, é certo que as pessoas repre- sentam os únicos verdadeiros agentes da empresa. Todos os ativos e estruturas, sejam eles tangíveis ou intangíveis, são resultados das ações humanas. Em última instância, todos dependem das pessoas. Não há dúvidas de que as empresas que não valorizam e potencializam os seus funcionários estão comprometendo seriamente seu futuro organizacional.

Isso pode ser observado por meio do fato de que as empresas sustentadas pelo conhecimento ostentam posição de destaque no mercado. $\mathrm{O}$ conhecimento está situado onde o funcionário se encontra, pois é ele que levanta a informação e desenvolve a base de conhecimento relevante ao trabalho. A esse funcionário interessa o crescimento da empresa e o seu aprimoramento pessoal e profissional. Por isso, o corpo funcional pode ser um importante laboratório de inovação, que atuará de modo adequado caso haja uma política firme, responsável, respeitosa e desenvolvedora do saber e das iniciativas (CARBONE, 2005).

Dessa forma, acredita-se que a gestão de pessoas deve participar ativamente na gestão do capital intelectual. Cabe a ela a preocupação com o desenvolvimento e a valorização do capital humano, entendido como os valores e as crenças, as competências individuais, as relações de trabalho, o estilo de liderança e os sistemas de comunicação e compartilhamento dos saberes. Prevalece, assim, uma consciência em formação de que o desempenho conquistado por qualquer empresa é resultado do capital humano disponível.

Por conseguinte, quanto melhor for o capital humano, maior será o resultado em termos de produtividade e lucratividade, tanto no presente quanto no futuro. Nesse sentido, um dos desafios fundamentais inerente à gestão de pessoas reside na identificação da correlação entre investimento em capital humano e resultados potenciais (CARBONE, 2005).

A área da gestão de pessoas está saindo cada vez mais de uma perspectiva processual para se voltar a uma ação 
mais sistêmica e estratégica, vinculada às necessidades da organização. Tal transformação pode ser vista nos novos modelos conceituais de ação de gestão de pessoas, direcionados para o fortalecimento do capital intelectual da organização. Embora os processos tradicionais não sejam desprezados, nasces uma nova dimensão de gestão de pessoas com uma visão estratégica e negocial, equilibrando as ações de curto, médio e longo prazos (CARBONE, 2005). Para Carbone (2005, p. 133),

Ao enxergar a empresa no longo prazo, a área de gestão de pessoas passa a perceber com mais clareza que as verdadeiras mudanças são alicerçadas nos valores e nas crenças, de forma lenta e gradual. Enquanto as áreas de negócios desejam um funcionário ativo, vendendo o máximo e atendendo o cliente da forma melhor possível, a área de gestão de pessoas precisa garantir que isso aconteça de forma sustentada. Que o bom atendimento e o excelente desempenho nas vendas sejam razão de profissionalismo permanente e responsável, e não fruto de um processo impositivo, gerador de estresse no presente e desentendimentos no futuro. Enquanto o negócio tende a olhar para o "aqui e agora", a gestão de pessoas precisa olhar para o futuro e suas consequências (grifo do autor).

As empresas necessitam, nesse contexto, potencializar ao máximo o seu capital humano, com o fim de assegurar seu sucesso futuro. No entanto, as pessoas não são propriedade da empresa - embora representem um ativo fundamental, não há relação de propriedade.

Dessa forma, algumas medidas, conforme Carbone (2005), tornam-se indispensáveis para que uma empresa se beneficie do capital humano gerado:

a. identificação do capital humano que gera riqueza - a empresa deve conhecer sua base de competência para poder administrar com excelência o seu capital humano. A partir do conhecimento das competências de cada funcionário e de quais são necessárias para o mesmo, torna-se mais fácil realizar o gerenciamento e o desenvolvimento de competências;

b. potencialização das competências dos seus funcionários - isso é possível por meio do aprimoramento do sistema de identificação e alocação de talentos, de modo a conduzir o funcionário a exercer atividades mais próximas à base de competências que detém;

c. promoção do compartilhamento das competências entre os funcionários - $\mathrm{o}$ desenvolvimento do valor compartilhamento representa a peça-chave na disseminação do saber na organização. Se os funcionários percebem que compartilhar conhecimentos é um valor interno admirado e recompensado, a empresa tende a desenvolver uma cultura de potencialização do saber.

Portanto, é essencial que a empresa identifique qual é o capital humano que gera riquezas. Para tanto, inicialmente, a empresa deve definir o que é capital humano nas organizações e em quais dimensões ele pode ser didaticamente dividido.

O capital humano não é somente o maior ativo de uma organização nem apenas a inteligência ou a base de competências dos funcionários, uma vez que a inteligência, quando tomada de forma isolada, não assegura qualquer valor organizacional. $\mathrm{O}$ funcionário pode não colocar sua inteligência à disposição do trabalho, por exemplo, o que poderia indicar inexistência de motivação (CARBONE, 2005). 
Carbone (2005, p. 135) ainda efetua outras considerações acerca da conceituação do capital humano:

O funcionário pode ser capaz de realizar bem determinada atividade e o seu gerente (ou pares) impedi-lo por ciúme ou inveja, o que indicaria falta de suporte gerencial. Podem ainda os recursos organizacionais à disposição dificultarem a boa realização de determinada tarefa. Nesse particular, pode faltar infraestrutura ou equipamentos de trabalho adequados. Definitivamente, o conceito de capital humano não pode ser olhado apenas na perspectiva da competência pessoal. Não deve ser entendido, também, como a "soma" linear das competências dos funcionários. Essa "soma" pode ser entendida como um ativo potencial, mas não como capital humano real (grifo do autor).

O capital humano precisa ser entendido, assim, com base na dimensão da competência, sustenta Carbone (2005). Pode-se afirmar que o capital humano inexiste sem base de competências, a qual necessita de suporte organizacional para ser criada, aprimorada, desenvolvida e exercida. Além disso, as relações de trabalho e a infraestrutura são determinantes para o exercício pleno da competência do trabalhador.

De fato, a inteligência isolada dos funcionários não gera produção alguma. Imprescindíveis são objetivos bem comunicados e compartilhados, diretrizes claras, liderança, entre outros aspectos. Sabe-se que, sem a infraestrutura e os equipamentos adequados ao trabalho, não é viável a realização das atividades com qualidade. Ademais, um trabalhador sem recompensa tende à desmotivação, não exercitando suas potencialidades.

Nessa perspectiva, Carbone (2005, p. 138) conceitua o capital humano como o "exercício pleno das competências humanas num contexto de trabalho". Essa definição é capaz de ampliar o foco do processo de investigação, comumente centrado na competência humana ou profissional. Trazer para o debate a dinâmica do contexto de trabalho é enxergar o ser humano na dimensão das suas relações e das suas necessidades fundamentais. Nessa linha de pensamento, dois focos de gestão e mensuração ganham destaque: o indivíduo e suas competências; e a organização e as dimensões de apoio ao exercício da competência humana no trabalho.

As competências humanas nem sempre são de fácil mensuração, de modo que um gerente despreparado pode inibir a competência de seu funcionário. É preciso, segundo Carbone (2005), que o contexto organizacional seja favorável a essa mensuração, ou seja, apresente valores, relações e condições de trabalho, bem como infraestrutura tecnológica para concretizar esse processo. O profissional traz consigo uma carga de conhecimentos, habilidades e atitudes que será mobilizada no ambiente de trabalho, motido pelo qual a qualidade desse ambiente é fator decisivo para o sucesso do trabalho e alcance de bons resultados por parte do capital humano.

Um ativo, para a contabilidade tradicional, compreende os bens e os direitos da entidade expressos em moeda. Tais elementos são classificados em ativos tangíveis e intangíveis. De forma simplificada, é possível afirmar que os primeiros são aqueles que possuem existência física e os segundos são os que não a possuem (ANTUNES, 2000).

Para Sandroni (2005), o ativo é constituído do conjunto de bens, valores, créditos e semelhantes que forma o patrimônio de uma empresa, opondo-se ao passivo, que é formado de dívidas e obrigações. $\mathrm{O}$ ativo pode ser dividido em circulante e fixo. No primeiro caso, incluem-se o dinheiro em caixa, os saldos bancários e todos os valores que podem ser convertidos em dinheiro imediatamente. No segundo caso, incluem-se os imóveis, os equipamentos, 
os utensílios, as ferramentas, as patentes e tudo aquilo que é importante para empresa continuar em operação e que não pode ser convertido em dinheiro de forma imediata.

Sandroni (2005) sustenta que os intangíveis representam a diferença entre o patrimônio líquido e o valor de mercado ou o coeficiente resultante da comparação dessas duas grandezas. O valor de mercado de uma organização advém da soma de seus valores tangíveis - instalações, máquinas, equipamentos, veículos, entre outros - e de seus valores intangíveis - know how e imagem.

A esse respeito, Antunes (2000) afirma que na prática empresarial, muitas vezes, torna-se difícil estabelecer uma diferenciação exata entre os ativos tangíveis e os intangíveis. Essa separação, contudo, é importante, pois afeta o valor real da empresa. Ademais, para Antunes (2000), a identificação de um ativo é fator primordial para o entendimento do capital intelectual, visto que o autor emprega o conceito econômico de ativo em contraposição à abordagem conservadora, que considera o agente como ativo.

A atribuição de valor a um ativo tangível comumente é mais simplificada do que a um ativo intangível. Isso se deve ao fato de que, via de regra, os ativos tangíveis possuem corpo, não necessitando de uma avaliação com maior grau de subjetividade. Já os ativos intangíveis são essencialmente marcados pelo grau de incerteza existente na avaliação dos futuros resultados que eles poderão proporcionar para a empresa.

Em uma realidade na qual o conhecimento representa a chave do sucesso de um negócio, afirma Carbone (2005), a gestão dos ativos intangíveis é essencial. É por meio da gestão desses ativos que a organização alcança seu crescimento e sua sustentação.

Também Antunes (2000) sustenta, que cada vez mais, as empresas têm dado atenção aos ativos intangíveis, os quais adquirem espaço na economia atual em sua totalidade e nas organizações. Merece destaque a valorização que se tem atribuído ao capital intelectual e ao capital humano.

$\mathrm{Na}$ atualidade, as organizações necessitam perceber que os seres humanos, em seu trabalho, não são apenas pessoas movimentando ativos, pois eles próprios se constituem como ativos que devem ser valorizados, medidos e desenvolvidos como qualquer outro ativo da corporação. Conforme salienta Ponchirolli (2005), são ativos dinâmicos cujo valor pode ser elevado com o tempo, e não ativos inertes que perdem valor.

No entender de Ponchirolli (2005, p. 118), os seres humanos, na verdade, constituem-se como os mais importantes ativos intangíveis de uma organização:

Com certeza, [os seres humanos] são os mais importantes de todos os ativos. Os sistemas criados para recrutá -los, recompensá-los e desenvolvê-los formam uma parte principal do valor de qualquer empresa - tanto quanto, ou mais, do que outros ativos, como dinheiro, terras, fábricas, equipamentos e propriedade intelectual. $\mathrm{O}$ valor da empresa e, portanto, o valor para o acionista (o valor das ações de uma empresa) podem ser depreciados, quando o capital humano é mal gerenciado.

No atual contexto econômico, o capital humano é marcado por dois grandes desafios. $\mathrm{O}$ primeiro deles diz respeito às limitações dos sistemas de medição e contabilidade. A noção de capital configura-se como uma noção a ser contabilizada, apesar de inexistirem normas para medição de seu valor, de modo que o capital humano ainda permanece, na maior parte das organizações, como um conceito vago, em vez de ser tomado como uma ferramenta a serviço do crescimento da organização. Dessa forma, é necessário que novos princípios sejam discutidos para que a empresa melhor possa empregar seu capital humano.

O segundo desafio existente concerne às limitações na perspectiva e nos 
motivos gerenciais. Os gerentes consideram difícil avaliar o capital humano em suas próprias organizações porque são parte vital desse capital. Apesar disso, é necessário que os gerentes promovam o conceito de capital humano e integrem-se à nova ordem.

Ao abordar a relevância dos recursos humanos e do conhecimento, Antunes (2000) salienta que o importante, nos dias hodiernos, não é a força humana. À medida que a tecnologia, por um lado, supre esse fator da força braçal, por outro, demanda inteligência pelo potencial humano. Entretanto, a percepção da inteligência não capta somente o quociente de inteligência, mensurado pela aplicação de testes específicos até então. Leva-se em conta, nas organizações, a inteligência emocional, a qual engloba aspectos como motivação e persistência diante de frustrações, autocontrole, habilidade de não permitir que a aflição impeça a capacidade de pensar e, sobretudo, relacionamento em grupo e empatia.

Mendes (2005) salienta que o conjunto dos ativos intangíveis de uma empresa tem sido responsável por uma parcela cada vez maior do valor financeiro dos produtos e serviços produzidos, visto que trazem uma quantidade sempre maior de conhecimento e, por conseguinte, de valor agregado. Nesse sentido, observa-se que o valor do capital intelectual advém também de sua relação com o conhecimento.

Inicialmente, para que se possa desenvolver a mensuração do capital intelectual, é preciso reconhecer que nem todos os ativos intangíveis de uma organização pertencem a ela. De acordo com Carbone (2005), enquanto os ativos intangíveis são propriedade da empresa, a maior parte dos ativos intangíveis não é propriedade sua. Os clientes, por exemplo, que se constituem como ativos intangíveis, não são propriedade da empresa. O mesmo ocorre em relação aos funcionários.

Portanto, não se trata de uma relação de propriedade, mas de um compar- tilhamento de objetivos. A empresa do conhecimento é aquela que tem competência para administrar grandes redes de colaboradores, sejam eles fornecedores, funcionários, prestadores de serviços, clientes ou demais agentes. Somente por meio do reconhecimento dessa relação de compartilhamento é que uma empresa pode gerar resultados crescentes com esses ativos (CARBONE, 2005).

Um modelo de mensuração de capital intelectual foi desenvolvido por Edvinsson e Malone (1998 apud ANTUNES, 2000), denominado de navegador Skandia, no qual o capital é a base de um esquema de valores que distingue os diferentes blocos que compõem o capital intelectual. Observa-se que os dois primeiros estágios representam a fórmula que os autores identificam como a do capital intelectual:

$\mathrm{CI}=\mathrm{Vm}-\mathrm{Vc}$, onde $\mathrm{Vm}$ é o valor de mercado e Vc é o valor contábil. Extraídos os dois tipos de capital que representam a composição básica do capital intelectual, a saber, capital humano e capital de estrutura, procedeu-se a uma sequência de mais duas subdivisões, resultando em mais dois subgrupos integrantes do capital estrutural.

Os estágios representados por áreas de capital servem de base para a identificação das áreas em análise na elaboração do modelo, possuindo cada uma seus respectivos indicadores: foco financeiro, foco no cliente, foco no processo, foco de renovação e desenvolvimento e foco humano (ANTUNES, 2000). As demonstrações financeiras empregadas para a determinação do foco assumem, assim, o papel de repositório de informações de feedback para análise e posterior avaliação de desempenho dos focos. À medida que a conversão de uma tecnologia se materializar em receita para a empresa, esta medida se desloca de renovação e desenvolvimento para clientes e processos, para, por fim, constituir um lançamento nas demonstrações financeiras. 
No que diz respeito ao foco no cliente, cabe salientar que as organizações na sociedade atual apresentam uma relação bem diferenciada com seus clientes, em comparação com a última década do século XX. Em virtude da revolução digital, surgiram novos tipos de produtos e serviços. Da mesma forma, emergiram novas categorias de clientes com exigências diferenciadas, bem como a necessidade de acompanhamento do cliente no pós-venda, tudo isso em um cenário econômico globalizado.

De acordo com Antunes (2000), essa nova realidade impacta não apenas a estrutura da organização, em termos de agilidade e flexibilidade, mas também as formas de avaliação, visto que a confiança, a lealdade e o compromisso com o cliente também se tornam valores perseguidos. Assim sendo, o sistema de valor real pautado no foco no cliente objetiva catalogar os indicadores que julga serem os mais aplicáveis para mensurar o real valor dos clientes. Essa tarefa consiste em encontrar os parâmetros que captam a nova realidade das relações eficazes e inteligentes entre a empresa e o cliente.

O valor real do foco no processo, por sua vez, trata da tecnologia como instrumento para apoiar a criação de valor global na empresa. No entanto, o investimento em bilhões de dólares em equipamentos eletrônicos não representa a garantia necessária para o aumento da eficiência e da produtividade, como muitas empresas ainda insistem em acreditar. Os erros cometidos nessa área podem comprometer a continuidade do negócio ou acarretar um desembolso maior para consertá-lo. Tais erros se refletem na escolha da tecnologia errada, na escolha de produtos cujos fornecedores não existem mais, tornando onerosa a manutenção e inviabilizando o upgra$d e$, e na crença de que a empresa deve se adaptar ao novo sistema, e não o contrário (ANTUNES, 2000).

A esse fatos, junta-se outro de significativa relevância, o da relação humana com as novas tecnologias que acarretarão mudanças nas organizações. A esse respeito, Antunes (2000) observa que o processo de mudança deve ser claramente explicado, no intento de evitar qualquer tipo de resistência ou sabotagem à nova tecnologia implantada.

Levando em conta tais aspectos, bem como a necessidade vital de investimento em tecnologia na atualidade, Edvinsson e Malone (1998 apud ANTUNES, 2000) elaboraram índices que pretendem demonstrar o valor da tecnologia nos relatórios. O sistema de avaliação para o foco no processo procura calcular índices que se enquadrem em quatro pontos:

a. atribuição de valor monetário à tecnologia de processo somente quando esta contribuir para o valor da empresa;

b. acompanhamento da idade e do atual suporte oferecido pelo fornecedor à tecnologia de processo da empresa;

c. avaliação não apenas das especificações do desempenho do processo, mas também da real contribuição de valor para a produtividade da empresas;

d. incorporação de um índice de desempenho de processo para as metas padronizadas deste desempenho.

Entre as vantagens do foco no processo, sobretudo levando-se em conta o conhecimento do capital estrutural, tem-se a contribuição para a decisão de investimentos em tecnologia da informação. A propagação e a massificação da tecnologia da informação têm conduzido muitas organizações a investirem grandes quantidades dos recursos financeiros em novos sistemas de informação e compras de softwares desenvolvidos especificamente para cada caso.

A rapidez com a qual os eventos se sucedem no mundo dos negócios 
pressupõe a agilidade na informatização das empresas em geral. Nesse sentido, uma avaliação da estrutura de tecnologia da informação disponível contribui para identificar as necessidades de novos investimentos, além de possibilitar a avaliação do uso dos sistemas implantados e do retorno que estes têm proporcionado à empresa (ANTUNES, 2000).

O foco na renovação e no desenvolvimento procura visualizar as oportunidades que irão definir o futuro da empresa. Seus respectivos índices, contrariamente ao caráter definitivo do passado da organização, captado por meio do foco financeiro, tentam projetar o futuro imediato, determinando o que a organização está efetuando no presente, a fim de se preparar de modo adequado para a captação de oportunidades futuras.

Embora seja difícil prever as mudanças que poderão ocorrer no futuro, há algumas áreas em relação às quais as empresas podem se precaver para as mudanças iminentes e, dessa forma, promover sua própria renovação como resposta. De modo resumido, essas áreas compreendem, segundo Edvinsson e Malone (1998 apud ANTUNES, 2000):

clientes - mudanças esperadas na base de clientes, nível atual de suporte aos clientes, frequência e eficácia da comunicação entre a empresa e sua base de clientes, índice de uso desse sistema pelos clientes etc.; atração no mercado - quanto a empresa está investindo em inteligência de mercado, qual o investimento no mercado atual e no mercado futuro, programas possuídos para rastrear novas investigações e novos concorrentes, evolução das marcas registradas e su imagem no mercado, entre outros aspectos;

produtos e serviços - produtos e serviços em desenvolvimento, possibilidade de serem lançados no mercado, velocidade de implementação de novos produtos, contribuição histórica de cada produto para a receita e o lucro da empresa, investimento efetuado no desenvolvimento de novos pro- dutos, número, idade e duração das patentes possuídas pela organização, número de patentes em etapa de registro, receitas atuais da empresa com licenciamento de suas patentes, etc.; parceiros estratégicos - investimento no desenvolvimento de parcerias estratégicas e no relacionamento com terceiros, custo e capacidade do sistema eletrônico de intercâmbio de dados entre a empresa e seus parceiros, informações corporativas que não podem ser trocadas com os parceiros, percentual de produtos da empresa projetado ou fabricado por terceiros, método usado para avaliar e estimular as operações de parceria, entre outros;

infraestrutura - itens como valor, idade e expectativa de vida dos instrumentos de apoio ao capital organizacional, aquisições de bens de capital planejadas para os próximos anos, percentual das receitas e dos lucros que será gerado por essas aquisições, configuração e valor do sistema de informação etc.;

empregados - nível médio de instrução dos colaboradores da empresa, número de funcionários por níveis de curso, quantidade média de horas mensais em treinamento por empregado, investimento anual e planejado em programas de recrutamento e seleção de empregado etc.

No que concerne ao valor real no foco humano, pode-se afirmar que uma empresa sem a dimensão de um fator humano bem-sucedido fará com que todas as demais atividades de criação de valor não funcionem, independentemente do nível de sofisticação tecnológica. A avaliação do foco humano constitui uma parte difícil do modelo de capital intelectual, de modo que qualquer mensuração referente aos colaboradores precisa considerar três dimensões: em primeiro lugar, é preciso que seja bem fundamentada, para não medir algo aparentemente importante, mas, na realidade, sem qualquer significado; na sequência, a mensuração deve ser bem estruturada, para não absorver as impurezas de outras variá- 
veis subjetivas; por fim, deve ser teleológica, isto é, relacionar a mediação e sua causa final, buscando, inclusive, refletir os valores em mudança na sociedade (ANTUNES, 2000).

O ser humano na sociedade do conhecimento, por ser ele o detentor de tal recurso, possui uma grande relevância dentro das organizações. O reconhecimento desse fato implica um novo desenho organizacional, criando novas categorias de trabalhadores e, por conseguinte, novas relações entre empresa e empregado.

Os grupos de trabalho que coexistem na moderna corporação resultam em níveis diferentes de lealdade e comprometimento organizacional, modificando, do mesmo modo, as estratégias motivacionais até então utilizadas. As novas relações de trabalho que são estabelecidas nas organizações compreendem basicamente: os empregados de escritório, que diariamente frequentem a empresa ou a fábrica e que possuem maior tendência de se fixarem em funções desgastantes ou de apoio aos que possuem base fora do escritório; os teletrabalhadores, que se constituem em uma nova classe de trabalhadores que, por meio dos avanços em telecomunicações, podem trabalhar em casa ou em algum escritório distante; os que atuam sempre fora do escritório, em diversos lugares, como vendedores, gerentes intermediários e executivos, permanecendo ligados constantemente à empresa por meio das novas tecnologias de comunicação; bem como aquele conjunto de empregados terceirizados, colaboradores em tempo parcial, consultores e empregados temporários.

Todo esse contingente de trabalhadores, segundo explica Antunes (2000), e sua dinâmica de atuação devem ser levados em conta quando a empresa pretende situar seu valor real no foco humano.

Independentemente da forma empregada para mensurar o capital intelectual, cabe destacar que este repre- senta uma fonte rica de informações sobre a organização em sua totalidade e, conforme Antunes (2000, p. 122) em um instrumento valioso para:

a. confirmar a habilidade da organização para atingir objetivos;

b. planificar a pesquisa e desenvolvimento;

c. fornecer informações básicas aos programas de reengenharia;

d. fornecer um foco para programas de educação organizacional e treinamento;

e. analisar o valor da empresa;

f. ampliar a memória organizacional.

Além disso, do ponto de vista interno da organização, pode-se somar como vantagem de investimento realizado para a mensuração do capital intelectual o fato de o conhecimento deste identificar os recursos necessários em ativos intangíveis cujo desconhecimento, por vezes, pode impedir a consecução de um planejamento estabelecido. De acordo com Antunes (2000), isso significa que o planejamento estratégico pode ser prejudicado pelo fato de depender de certos elementos intangíveis e de a empresa não apresentar certeza de que dispõe ou não de tais recursos (e dispondo, não saber a quantidade nem a possibilidade de geração futura).

Por meio do conhecimento do capital estrutural, conforme indicado no modelo de Edvinsson e Malone (1998 apud ANTUNES, 2000), pode-se distinguir criação de patentes, desenvolvimento de novos designs e desenvolvimento de novos produtos, passando a identificar as vantagens competitivas que cada um desses elementos possui. Outra vantagem obtida por meio da mensuração do capital intelectual diz respeito à situação em que é necessário que a empresa efetue redução de número de funcionários. Nesse caso, o conhecimento do capital humano impe- 
de que os cortes afetem as pessoas com conhecimentos valiosos para a organização - um exemplo positivos, nesse sentido, são os programas de demissões voluntárias, desenvolvidos por muitas empresas.

Ademais, Antunes (2000) sustenta que o conhecimento do capital humano também contribui para as decisões de investimentos em treinamento. Uma empresa que possui um relatório de capital humano pode optar pelo treinamento mais adequado, levando em conta as necessidades identificadas em seus ativos humanos, assim como proceder a uma avaliação posterior, no intento de mensurar os benefícios obtidos.

Ao analisar esse modelo de Edvinsson e Malone, Carbone (2005) afirma que eles se utilizam dos mesmos princípios do balanço contábil tradicional, embora a tradução numérica constitua uma dificuldade, visto que muitos indicadores de capital intelectual não são financeiros. Outro importante modelo de mensuração e gestão do capital intelectual é o balanced scorecard (BSC), desenvolvido por Kaplan e Norton. Kaplan (1999) sustenta que o BSC se apresenta como um modo de compreender os fatores que influenciam a receita da empresa.

Kaplan e Norton conceituam o BSC como uma ferramenta por meio da qual é possível traduzir a visão e a estratégia da empresa em um conjunto coerente de medidas de desempenho. Nesse conjunto de medidas de desempenho, situam-se as financeiras, responsáveis por avaliar o desempenho passado, e as não financeiras, responsáveis por impulsionar o desempenho futuro (KAPLAN; NORTON, 1997).

Assim, o funcionamento do BSC ocorre por meio de um sistema que integra os indicadores financeiros e não financeiros. Para tanto, são utilizadas quatro perspectivas equilibradas: financeira, clientes, processos internos e aprendizado e crescimento. $\mathrm{O}$ indicador financeiro informa como a orga- nização é vista pelos seus acionistas; o indicador clientes informa como ela é percebida pelos clientes; o indicador processos internos centra-se no desempenho dos processos de negócios nos quais se deve alcançar a excelência; e o indicador do aprendizado e crescimento está centrado no modo de sustentar a capacidade de mudanças e de melhorias (KAPLAN; NORTON, 1997 apud ZORZI et al., 2006).

Carbone (2005) também sustenta que são quatro os elementos ou as perspectivas de avaliação contidas no BSC. A perspectiva financeira indica se a estratégia da empresa, sua implementação e execução contribuem continuamente para a melhoria da produtividade. Essa perspectiva engloba medidas como: retorno sobre investimento, crescimento da receita e lucratividade por produto/ serviço/cliente.

A perspectiva de clientes contém medidas fundamentais de resultado ligadas à satisfação dos clientes, à retenção e aquisição de novos clientes, à fatia de mercado com clientes-alvo, à entrega pontual, ao tempo de respostas, entre outros.

A perspectiva de processos internos indica o sucesso da organização em termos de desenvolvimento de processos indispensáveis aos negócios. Inclui medidas como: tempo necessário para desenvolver a próxima geração de produtos, percentual de lançamento de novos produtos, percentual de venda de novos produtos, índices de qualidade e eficiência da mão de obra e dos equipamentos.

Por fim, a perspectiva de aprendizado e crescimento pretende conhecer o sucesso da empresa quanto ao treinamento dos funcionários, à melhoria da base de infraestrutura e de sistemas de informação, ao alinhamento de valores e ao compartilhamento de conhecimentos. Entre as medidas, as seguintes merecem especificação: satisfação do funcionário, rotatividade e retenção de talentos, tempo de ciclo de retreinamen- 
to, sugestões dadas pelos funcionários, percentual de funcionários com metas de desempenho ligadas à estratégia da empresa, prontidão do capital humano e dos aplicativos estratégicos, compartilhamento das melhores práticas, valor agregado por funcionário e lucratividade por funcionário (CARBONE, 2005).

De acordo com Carbone (2005), o BSC teve importante repercussão no ambiente empresarial por estar diretamente ligado aos métodos e às ferramentas de gestão estratégica, comuns em organizações de grande porte. Atualmente, na sociedade do conhecimento, ativos intangíveis como a lealdade dos clientes e as competências dos funcionários são igualmente ou até mais importantes do que os recursos intangíveis - estes se convertem naqueles quando apoiam diretamente a estratégia.

No entender de Kaplan e Norton (2004, p. 205):

Os ativos intangíveis adquirem valor apenas no contexto da estratégia, para cuja execução devem contribuir. [...] O papel estratégico dos ativos intangíveis não pode ser abordado de maneira isolada. É necessário um programa integrado para suportar o aprimoramento de todos os ativos intangíveis da organização.

Com base na realização do alinhamento e da integração, obtêm-se os elementos fundamentais em termos de conceito para que se possam desenvolver os objetivos de capital humano, de capital da informação e de capital organizacional, na perspectiva do aprendizado e do crescimento. No entanto, segundo Kaplan e Norton (2004), ainda são poucas as organizações que exploram as vantagens competitivas potenciais resultantes do alinhamento e da integração de seus ativos intangíveis.

Para proporcionar esse alinhamento entre estratégia da empresa e ativos intangíveis, Kaplan e Norton (2004) propõem a construção de mapas estratégicos. Esse mapa promove o alinhamen- to e a integração ao fornecer um ponto de referência comum para a estratégia da empresa. A perspectiva interna do mapa identifica os poucos processos críticos que criam os resultados esperados para os clientes e acionistas. Os ativos intangíveis devem estar alinhados com esses processos internos que criam valor.

Kaplan e Norton (2004) propõem três técnicas de alinhamento para realizar a construção de uma ponte entre o mapa estratégico e os ativos intangíveis:

a. funções estratégicas - para cada processo estratégico, uma ou duas funções estratégicas exercerão maior impacto sobre a estratégia. Ao identificar essas funções, definir suas competências e promover seu desenvolvimento, torna-se possível acelerar a realização dos resultados estratégicos;

b. portfólio estratégico de tecnologia de informação - sistemas e infraestrutura específicos de tecnologias de informação permitem implementar cada processo estratégico. Esses sistemas representam um portfólio de investimentos em tecnologia que precisam receber prioridade na alocação de financiamentos e de outros recursos;

c. agenda de mudança organizacional - a estratégia exige alterações nos valores culturais, orientadas tanto para dentro, como no caso do trabalho em equipe, quanto para fora, como ocorre quando o foco é o cliente. A agenda da mudança cultural, extraída da estratégia, auxilia a nortear o desenvolvimento de nova cultura e novo clima.

Assim, a partir do momento em que a empresa alinha e integra seus capitais humano, da informação e orga- 
nizacional, compatibilizando-os com poucos processos críticos, gera maior retorno para os seus ativos intangíveis (KAPLAN; NORTON, 2004). Embora em um primeiro momento pareça incoerente falar em mensuração de ativos intangíveis, alguns critérios de medição se destacam com clareza, sustentam Kaplan e Norton (2004), de modo que os ativos intangíveis não deveriam ser medidos pelo dinheiro gasto em seu desenvolvimento nem por análises independentes sobre capacidades e contribuições de ativos de recursos humanos e tecnologias de informação.

$\mathrm{O}$ valor dos recursos intangíveis resulta da efetividade do seu alinhamento com as prioridades da organização, e não do quanto valem em termos isolados. Quanto mais estreito for o alinhamento dos ativos intangíveis com a estratégia, maior será o seu valor para a organização. Do mesmo modo, os ativos intangíveis que não estiverem alinhados com a estratégia não criarão muito valor, por maior que tenha sido o seu custo (KAPLAN; NORTON, 2004).

Para a mensuração dos ativos intangíveis, pode-se, então, recorrer a alguns princípios contábeis empregados na avaliação dos ativos tangíveis e financeiros da organização. Os contadores classificam o lado do ativo do balanço patrimonial em categorias, como caixa, contas a receber, estoques, imobilizado e investimentos em longo prazo. Os ativos são ordenados de maneira hierárquica tendo por base o seu critério de liquidez ou a facilidade com que são convertidos em caixa.

Kaplan e Norton (2004, p. 216) assim estruturam essa pirâmide de mensuração dos ativos intangíveis:

Contas a receber é mais líquido (converte-se em caixa com mais rapidez) do que estoques, e ambos são classificados no ativo circulante, pois quase sempre se transformam em dinheiro em menos de doze meses. Os ativos de longo prazo (ou permanentes), como sugere o nome, levam mais tempo para se converterem em caixa. Por exemplo, o ativo imobilizado fornece capacidade para a transformação de matérias-primas em estoques de produtos acabados, que, depois de vendidos, viram contas a receber e, finalmente, geram caixa. Mas são necessários muitos ciclos de conversão para que se recupere o investimento inicial em imobilizado.

$\mathrm{O}$ arcabouço do mapa estratégico disponibiliza as condições essenciais para que os capitais humano, da informação e organizacional sejam representados como ativos, os quais terminarão por ser convertidos em caixa, o mais líquidos dos ativos, por meio do aumento da receita e da redução das despesas.

Kaplan e Norton (2004) introduzem, então, o conceito de prontidão estratégica como meio de descrever o grau de preparação dos ativos intangíveis tendo em vista a necessidade de suportar a estratégia da organização. A prontidão estratégia assemelha-se à liquidez, de forma que, quanto mais alto for o nível de prontidão estratégia, maior será a rapidez com que os ativos intangíveis contribuirão para gerar caixa.

A prontidão estratégia convertese em valor tangível somente quanto os processos internos criam níveis cada vez mais elevados de receita e lucro. Muitas vezes, as organizações não são capazes de atribuir valor financeiro significativo a fatores intangíveis, tais como a força de trabalho motivada e preparada, visto que eles somente geram valor tangível no contexto da estratégia.

\section{Considerações finais}

Com base na perspectiva financeira do mapa estratégico, torna-se viável afirmar que a execução bem-sucedida da estratégia gera crescimento da receita e aumento do valor para os acionistas. A força de trabalho que alcançou níveis satisfatórios de prontidão estratégia é um, mas somente um, dos fatores que permitem o aumento 
da receita ou a criação de valor para os acionistas. Dessa forma, a prontidão do ativo intangível capital humano é condição indispensável, mas não suficiente, para o sucesso da estratégia (KAPLAN; NORTON, 2004).

Ao avaliar os sistemas de mensuração apresentados, Carbone (2005) sustenta que o valor de mercado de uma empresa é sempre formado pelo seu patrimônio visível ou líquido, juntamente com o patrimônio invisível ou intelectual. Na realidade, o capital intelectual tem uma inspiração capitalista de apropriação, permitindo resgatar e atribuir valor a importantes dimensões, entre elas a do capital humano.

Essas dimensões intangíveis, cada vez mais, constituem-se como uma preocupação de empresários e investidores, promovendo a proteção econômica do investimento de risco de longo prazo. Destarte, a identificação e a mensuração dos ativos intangíveis asseguram a proteção desse patrimônio dos investidores, que podem comercializá-lo com mais exatidão e segurança (CARBONE, 2005).

Outro aspecto relevante a ser observado e presente nos sistemas em geral de mensuração dos ativos intangíveis diz respeito ao fato de que o capital intelectual de uma organização é sempre não financeiro e representa a lacuna oculta entre o valor de mercado e o valor contábil. Aqui, segundo Carbone (2005), pode-se notar uma ambiguidade importante: o capital intelectual é classificado como capital não financeiro, embora assuma valor econômico em dado momento, que pode ser na venda da empresa, na valorização ou na desvalorização dos preços de suas ações no mercado. Dáse um valor monetário àquilo que, em essência, não é financeiro.

Os sistemas de mensuração dos ativos intangíveis também consideram que o capital intelectual é um passivo, e não um ativo, devendo ser entendido de modo idêntico ao patrimônio líquido. Por isso, deve ser considerado um empréstimo feito pelos credores, ou seja, pelos clientes, funcionários, acio- nistas, e assim por diante. Nesse ponto, revela-se à prática do setor financeiro de somente conceder empréstimos para investimentos garantidos por patrimônio tangível. Quando se analisa o balanço contábil, o financiamento é visível e consiste em cotas de participação acionária e empréstimos.

Por outro lado, os ativos intangíveis são financiados, sobretudo, por meio do patrimônio invisível dos acionistas, que se forma a partir da diferença entre o valor contábil e o valor de mercado. Também se levam em conta, nesse financiamento, as obrigações contingenciais para com os funcionários, como indenizações e privilégios, por exemplo. Isso resulta da relutância dos bancos em conceder empréstimos para investimentos em ativos intangíveis, sem caução tangível para assegurar o retorno. No entender de Carbone (2005), esse tipo de ação, de bloquear o crédito às organizações de conhecimento, significa impedir que o conhecimento prospere em escala mais rápida.

Os modelos de mensuração de ativos intangíveis consideram, ainda, que o capital intelectual é uma informação complementar, e não subordinada às informações financeiras. Essa perspectiva pode colocar em xeque os métodos de trabalho dos contadores, auditores e controladores, sustenta Carbone (2006).

A tentativa dos pesquisadores que defendem a mensuração de capital intelectual é de aproximação com a categoria de contadores, evidenciando os benefícios do modelo sem desconsiderar a relevância dos indicadores financeiros. Diversos estudiosos entendem que seria inviável a categoria dos contadores modificar de modo radical os seus métodos de trabalho. Ainda assim, prevalece o entendimento de que, com o passar do tempo, certamente os contadores adaptar-se-ão à nova realidade, processo esse que já perpassou diversas outras profissões que tiveram seus métodos de trabalho questionados (CARBONE, 2005). 


\section{Referências}

ANTUNES, M. T. P. Capital intelectual. São Paulo: Atlas, 2000.

CARBONE, P. P. Gestão por competências e gestão do conhecimento. Rio de janeiro: FGV, 2005.

KAPLAN, R. S. Dos custos à performance. HSM Management, São Paulo, v.13, p.6-11, mar./abr. 1999. Entrevista concedida a José Salibi Neto.

KAPLAN, R. S.; NORTON, D. P. A estratégia em ação: balanced scorecard. Rio de Janeiro: Campus, 1997.

KAPLAN, R. S; NORTON, D. P. Mapas estratégicos: convertendo ativos intangíveis em resultados tangíveis. Rio de Janeiro: Campus, 2004.

MENDES, S. P. Gestão do conhecimento individual. Florianópolis: Visual Books, 2005.

PONCHIROLLI, O. Capital humano: sua importância na gestão estratégico do conhecimento. Curitiba: Juruá, 2005.

ZORZI, A. et al. Balanced scorecard: alicerce de um modelo de gestão para uma entidade fechada de previdência complementar. In: Congresso Brasileiro de Custos, 13., 2006, Belo Horizonte. Anais... Belo Horizonte, out./nov. 2006. 